\title{
The Connection for Cultural Meaning: A Way to Develop Zhuhai Culture Industry
}

\author{
Han Ruihui \\ Humanities School, Jinan University \\ Zhuhai, Guangdong Province, China \\ hanruihuihh@hotmail.com
}

\begin{abstract}
Culture industry is vital for the local economic development in many contemporary China cities, especially for Zhuhai, a city is developing culture industry in recent years in the background that culture industry provides strong impetus for economy. Zhuhai is a city renowned for its beautiful scenery and fresh air in China with the development of tourism for many years, so the development of culture industry is critical for Zhuhai's future economy progress since the manufacturing industry will bring about many adverse effect for the current economic condition for Zhuhai. Previous research has argued for more investment for Zhuhai culture industry and constructing more buildings about culture industry. However, previous research has ignored the existing condition that can be used for the development of culture industry in Zhuhai because single investment for culture industry without the using of existing condition would cause waste and inefficiency. This article addressed the neglected aspect and believes the connection of the existing buildings and projects can generate the new cultural meaning, which is lacked in Zhuhai compared with the condition in other China cities. The article concludes that the predominant universities and the abandoned factories is two significant advantages for Zhuhai's culture industry. To connect them with other projects and buildings can produce the positive impetus. The findings presented in this article add to our understanding of the culture industry development strategy.
\end{abstract}

Keywords: culture industry; Zhuhai; universities; abandoned factories; connection.

\section{INTRODUCTION}

In the new global economy, culture industry has become a central issue for the local economic development. Zhuhai city is the famous tourism resort in China for its beautiful landscape and fresh air. The tourism economy is also the main fiscal revenue of Zhuhai government, with many factories removed for the main urban area in recent year for the promotion of the tourism economy and the improvement of landscape and air. In the background, Zhuhai city also wants to develop the culture industry, because culture industry is compatible and complementary with the tourism economy. However, with the tourism economy as the main revenue, Zhuhai culture industry is not the first-rate in Guangdong province. The previous researches about Zhuhai culture indicate that firstly the culture industry economy too weak to drag the whole Zhuhai economy forward, secondly Zhuhai lacks of the leading enterprise and the industry structure need to be optimized. Thirdly, Zhuhai culture industry is in short of the development platform. Fourthly, the industry culture system should be improved. ${ }^{1}$

With a variety of definitions of the term "culture industry" have been suggested in history, this paper will use the definition stipulated in The Suggestions for Improving the Culture Industry Development issued by China culture ministry. According to the definition stipulated in The Suggestions (2003), culture industry can be defined as follows: "culture industry is the commercial industry that involved in the culture production and culture service."

The past twenty years have seen increasing interest of China government and research institution in the development of culture industry, some researchers or officials proposed that culture industry should be invested more and more culture industry talents should be employed. However, in the

\footnotetext{
1 According to the Department of Zhuhai Culture Industry and Policy Response (Zheng Jiangyong, The Department of Zhuhai Culture Industry and Policy Response, Zhuhai Daily. 008. May 24 , 2015.), Zhuhai culture industry has many shortcomings.
} 
process, the use and combination of the new culture industry and old industry are neglected. Despite the previous industry in Zhuhai has nothing to do with the culture industry, the previous industry can be the basis of the culture, and some of the manufacture industry can also be transformed into the culture industry, for example, the factories that abandoned can be used as the base of the culture industry. Some universities are also the preconditional advantage for development of Zhuhai's culture industry.

Because of the previous tourism economy development of Zhuhai, central to the entire Zhuhai culture industry development is how to make use of the advantages of Zhuhai tourism resource and the others. For many cities in China, the combination of the previous advantage and the corresponding culture industry development is important for that the previous economic development provides the basis for the later culture industry. This article will provide the investigation on such problem.

\section{Previous Research on Zhuhai Culture Industry and Relevant Solutions}

Ever since the 11th Five-Year Plan, Zhuhai has made great progress in culture industry, the industry of online game, movie, creative design, modern media, leisure and recreation all showed the powerful development trend. (He Xin, 2011) The speed became faster and the contribution to the revenue became more in the sphere of culture industry, besides, some competitive industries appeared in recent years. There are also some local culture industry with local features in recent years. The system that promotes the culture industry is also constructed. (He Xin, 2011)

However, previous studies also have reported that Zhuhai culture industry had some problems overall: 1) Zhuhai culture industry had no brand image; 2) there was no platform for Zhuhai culture industry; 3) some officials and citizens did not recognize culture industry as the decent industry for Zhuhai economy; 4) the culture industry talents were not enough in Zhuhai for culture industry. (Chen Huixian, 2007) Some specific culture industries are still not satisfactory, for example, as for the marine culture industry, some researchers noticed that Zhuhai natural tourism resource, the historical culture and folk culture were not developed enough, and the tourism talents were not enough or the current tourism were not qualified, besides, the staying time of the tourists in Zhuhai was short and the commercial function of the rich marine culture was limited. (Xie Shisheng,2008) Although there were some manufacture factories of culture industry in Zhuhai, the cultural creative industry was scarce. (He Xin, 2011) Although defects of Zhuhai culture industry is the focus of the research, there is very little published research on how Zhuhai use the current resource and the previous economic accumulation to build Zhuhai culture industry. Most studies in the field of Zhuhai culture industry have only focus on the human resource and the platform of culture industry itself.

Some researchers noticed the abandoned factories could be used as the base of culture industry, or the factories would become the waste and that was also the damage for China economy, just as Cao Pangong argued in his thesis: "the urbanization of our country is developing rapidly, the situation of construction and destruction without layout is very serious. In the modern city, many old buildings were dismantled completely. The negative impact is the separation of culture context and structure. And this, in a great degree, resulted in the waste of resources. "(Huang Pangong, 2007) The reformation of the abandoned plants provides new meanings for the space in this case. We can also regard the process as the meaning generation by the connecting the abandoned factories and their circumstance or the past because connection would generate new meanings about the preconditional objects.

In this article, I will address how the connection between the existing object can provide the impetus for Zhuhai culture industry. The relationship of economic accumulation, existing cultural objects and culture industry is critical for Zhuhai city. The aim of this study was to investigate such relationship and that will shed new light on the perspective of Zhuhai culture industry development.

This paper begins by the analysis of Zhuhai current culture industry situation, it will then go on to analyze the opportunities and the weakness of Zhuhai culture industry, in the next section, the paper will examine how to make use of the advantages and previous economic accumulation of Zhuhai culture industry. The following section will address the problem more theoretically in the perspective of the relationship between narrative and culture. 


\section{The Defects FOR ZhUhAI's Culture INDUSTRY EsPecially THE IsOlated Condition of Physical Culture ObJects}

Zhuhai culture industry itself is weak overall. That is embodied in the aspects of its position in culture industrial chain, human resources, the attitudes of the government and the historical factors.

The development structure of Zhuhai culture industry is not rational and the coral cultural production value is not high and the culture industry is prompted by other affiliated culture product's production and market. Although culture industry of Zhuhai is large, the production of culture industry of Zhuhai is in the downstream of industrial chain. (He Xin, 2011) As a tourism resort, Zhuhai has the advantage to promote the culture industry, however, the talents of culture industry in Zhuhai are limited. ${ }^{2}$ Such condition is faced with many cities which want to develop culture industry. Although Zhuhai has many high schools, and the number of high schools in Zhuhai is the second in Guangdong province. However, in recent years, the graduated students in Zhuhai high schools are even not enough for creative cultural industry. In the first, the creative cultural industry majors in Zhuhai high schools are rare in the condition that the correspondent teacher resource is too weak to establish this major. Secondly, even several high schools in Zhuhai city establish creative cultural industry majors, the students are not enough for Zhuhai creative cultural industry in the condition many students graduated from such major would not all choose the creative cultural industry job. From above description, we can find that Zhuhai creative cultural industry lacks of the related talents. The condition that Zhuhai creative cultural industry lag behind is also caused by the negative attitude toward such industry. For many people, the creative cultural industry may mislead the juvenile and only has the pretentious name but not the actual content. (Chen Huixian, 2007)

Besides, according to the previous research, the attitude of Zhuhai government toward culture industry also lag behind in the condition that Zhuhai government advocated the policy of "economy plays on the stage built by culture". So in such condition, the leading actor is still the economy only and the culture aids the economic development. (He Xin, 2011) Zhuhai Government does not recognize the soft power of culture. (He Xin, 2011) The soft power of culture industry can not play its role in short time, so it is naturally that many people do not trust that the culture industry can bring the profit as other kinds of industry do. Previous research has reported that the mechanism of Zhuhai culture industry is rigid, just as He Xin argued: "the reforming of cultural system is slow. Many cultural institution has the egalitarian practice with the rigid human resource policy. The advocating for culture industry is not enough and the circumstance for culture industry need to be improved." (He Xin, 2011)

Compared with many other cities which are renowned for their tourism, Zhuhai lacks the historical culture meanings. The historical artificial cultural mark in Zhuhai city is rare. When the tourists arrive in Zhuhai city for t travelling, they would enjoy the beautiful natural sensory and fresh air, but the cultural meaning association caused by the artificial mark is seriously rare. The Baiteng lake in Zhuhai is only the physical water, however, the Xi lake in Hangzhou city has not only the physical water but also the cultural meanings because there many renowned poems and legends about Xi lake. Because of the historical reasons, Baiteng lake has not so much cultural resource. So even the two lakes are almost the same in physical appearance, however, the effects of them on the travelers are totally different. Historical culture accumulation plays important role in the process. Historical culture accumulation is a kind of culture brand, which is critical to the culture industry development. Compared with beautiful scenery and fresh air in Zhuhai, such culture is dim and that results in the inactivity of Zhuhai culture industry and cultural attraction.

\footnotetext{
${ }^{2}$ Some cities want to develop the culture, however, the talents are limited because in China, the related talents cultivated in high schools are not enough. Although China wants to develop in culture industry in recent years, the major of cultural creative industry major in China is not as common as other traditional majors. Dongguan city is typical in the dilemma of developing culture industry. The animation town in south Dongguan city, the creative cultural industry district in east Dongguan city, Xiatang Shuilong oil painting village, the creative industrial center of Dongguan and Tailang creative cultural industry center are all developed less than satisfactory because the creative cultural industry talents are not enough. (Dong Jianqing. Study on the Reuse Strategy of Old Industrial Building in Dongguan. Master Thesis. South China University of Technology. December 2014. Pp24-26
} 
It is interesting to point out the isolated condition of Zhuhai's culture buildings and projects, which is also a serious defect of Zhuhai's culture industry development and are neglected by previous research. Different from other cities, Zhuhai is a city of short history and scarce culture. Most of the population in Zhuhai are the immigrants, besides, the historical buildings are also rare, but Zhuhai has lots of brand new buildings or projects which have unique cultural meanings, for example, New Yuanming Palace in Xiangzhou district of Zhuhai city and the food festival every year in Zhuhai. However, the projects or the buildings are isolated from Zhuhai background. The buildings or projects' cultural meanings are derived from other places, but not Zhuhai city. When people appreciate the buildings or projects, they would associate the stories or other cultural meanings derived from other places. But it can not be said that such buildings or projects can not bring cultural meanings to Zhuhai. They are only exist separately in Zhuhai and seems detached or alienated from Zhuhai city background. So in the sense, those buildings or projects has the isolated cultural meanings for Zhuhai.

\section{The Advantages Especially the Abandoned Factories and the Booming UNIVERSITIES FOR DEVELOPING CULTURE INDUSTRY}

The current literature has emphasized the following advantages of Zhuhai in development of culture industry: 1) Zhuhai has the long historical human resource; 2) the advantage of excellent natural circumstance; 3 ) the advantage of the special economic zone; 4) the advantage of being the neighbors of Hongkong and Macau. (He Xin, 2011) A great deal of previous research into the advantages of Zhuhai in development of culture industry has focus on the advantages mentioned above. However, besides the advantages mentioned above, Zhuhai has some other advantages for developing culture industry.

\subsection{The Abandoned Factories}

There are more than 78 manufacturing districts in Zhuhai, and most of them congest in the east part of Zhuhai, where is for the development of culture industry according to the municipal government's plan. In recent years, many factories emigrated from east part to the west part of Zhuhai, where was planned to be the main manufacturing base of Zhuhai in order to prevent the serious pollution of the east part, where is population concentrating. Some of Zhuhai manufacturing districts even moved to Jieyang, a city far from Zhuhai.

So there is many manufacturing plants left by the previous factories, and some of them almost become something like ghost towns. For example, Cuijing manufacturing district, an area contained more than 100 thousand peasant-workers, was abandoned in recent years in the result that the number of peasant-workers decreased to less than 30 thousand. Cuijing manufacturing district is in the border of Zhuhai and Zhongshan city, but such area is significantly prosperous, because of the peasant-workers concentrate here. Beside Cuijing manufacturing district, there is Shisi village, a place of Zhongshan city where the peasant-workers live in because of the lower living cost than in the areas in Zhuhai. The manufacturing factories have the long history since the economic reforming of 1979, when the government of China gave the preferential treatment for the enterprises, especially the enterprises established by the entrepreneurs came from Taiwan, Hongkong and Macau. This manufacturing district has many huge plants, which are spacious or even dignified because they were built many years ago with the building style that was different from contemporary times. It is interesting that beside the manufacturing district, the environment is excellent because of the long existing attitude of Zhuhai government for environmental protection. The abandoned manufacturing district's exterior has the following values: 1) the value of the manufacturing district's exterior is the non-renewable resource which reflects the passed manufacturing industrial civilization; 2) it has the value of historical materials; 3) the value that promotes the cultural identity; 4) value of the industrial aesthetics. (Cheng Ying, 2014)

In summary, it shows from above description that Cuijing manufacturing district has the concentrating population, the long history, the convenient living circumstance and, of course, the specious and dignified plants. The environment around the district is also excellent. All those constitute the base for the culture industry. The example shows that Zhuhai has some unique advantages provided by the previous factories and the measures is called for making use of such plants. 


\subsection{The Booming Universities}

\subsubsection{The Development of Universities in Zhuhai City and Culture Industry}

Zhuhai has 10 universities: Zhuhai campus of Zhongshan university, Zhuhai campus of Jinan university, Zhuhai college of Beijing Normal University, Beijing Institution of Technology, Zhuhai College of Jilin University, United International College, Zhuhai college of Zunyi Medical University, Zhuhai college of Guangdong Institute of Science and Technology, Zhuhai City Vocational and Technological College and Zhuhai Art Vocational College. ${ }^{3}$ In Guangdong province, Zhuhai has the second largest university park, so the university park in Zhuhai can play an important role in the culture industry development. Until 2011, the area of Zhuhai universities in total is 25095 acres. (Guangdong Association of Higher Education Research, 2012) The universities have some shortcomings: 1) the local government has no enough administration right to the universities, so the coordination between administrations of the local government of higher government for the universities is hard; 2) the level of the universities is not high in general; 3) the progress of science research is slow with the limited use of main campus's high quality recourse. (Guangdong Association of Higher Education Research, 2012) From the research of the Zhuhai university park development, we can find that the universities' development is unsatisfactory. Correspondently, the culture industry of Zhuhai city will also be affected adversely, because the universities is one constituent part of Zhuhai culture industry.

The coordination between the local government with the higher government who administrated some of the universities is important, because some of the local resources can be combined with the universities to achieve better result. For example, New Yuanming palace can be integrated into Jinan University, the neighbor of New Yuanming Palace. New Yuanming Palace is one tourism park in Zhuhai. The park is administrated by Zhuhai government. Its neighbor Jinan University Zhuhai campus is administrated by Jinan University main campus in Guangzhou, which is administrated by Overseas Affairs Office in the State Council. The two units operate and be administrated separately, so their resources can not be shared and the optimized result can not be achieved. Jinan University Campus has the area of more than 800 acres and the number of more than 7000 students in 2010 . (Jinan University Zhuhai Campus, 2010) In recent years, the recruit student number and the teachers became more with the better quality of teaching and research. But the campus of Jinan University in Zhuhai is small, so the development of it would be limited by the area, for example, the recruit number of students would be hampered. In 2014, New Yuanming Palace is free to the visitors. The tourism effect is not good for New Yuanming Palace, because Yuanming Palace is one famous relic of Qing dynasty imperial family in Beijing, however, far from Beijing, in south China, New Yuanming Palace was built. So the park has no cultural background since Yuanming Palace relic is in Beijing, north China. When the tourists visit New Yuanming Palace, they would associate with north China, but not South China, or specifically, Zhuhai. So if we integrate New Yuanming Palace into Jinan University, they would both achieve the better result. When the tourists visit New Palace, they would also in the campus of Jinan University, so they would get more cultural enjoyment. The activities of students would revive the park and bring into new cultural meaning to it. On the other hand, the park would also provide the area for development of Jinan University. Zhuhai has the advantage to make use of campuses, because those campus can provide Zhuhai with more cultural meaning in the background that Zhuhai lacks of the long history and prosperous culture, just as Chen Changgui argued: "Zhuhai university park can cultivate the cultural literacy of the citizens, and enhance the competitive of Zhuhai in the sphere of culture."(Chen Changgui, 2007) Some famous universities, such as Jinan University and Zhongshan University, can play critical role in Zhuhai culture industry.

\section{The NeCESSity to MAKe uSE OF THE Existing ResourCe}

Some researchers have pointed out that the adverse result of greedy pursuit for the new buildings and the urban area. "The urbanization of China is facing with the influence from westernization, traditionalism and the opinion of synthetic creation. The emphasis on culture is lacked in main cities

\footnotetext{
3 According to Innovation and Integration to Strengthen Zhuhai University Park Status Quo, Problems and Advices. (Guangdong Association of Higher Education Research, Innovation and Integration to Strengthen Zhuhai University Park Status Quo, Problems and Advices. Chinese Higher Education. 2012(11), pp17-20.(in Chinese)
} 
of China or the city culture is not normal. The construction of cities pursuits only for being higher, huger and more gorgeous. The local cultural tradition, custom and own resource are neglected, so the cities become more and more similar and without the indigenous features. The buildings, especially the landmark has more and more vulgar culture. " (Zhao Hong, 2007) To some extent, the economy and culture are opposite to each other in some cities of China. Many China buildings imitate the western construction style so much that the Chernobyl disaster happened in China buildings: the coordination of construction style is uncontrollable and self-contradictory. (Fu Chonglan, 2005)

In the construction of urban, many cities is have the same scenery, for example, "window of the world" exists in Shenzhen, Changsha, Guangzhou, Hangzhou and Shanghai. "Liangshan marsh" was developed with huge budget in Wuxi, Wuhan, Baiyangdian in Hebei province and Shandong province. (Zhu Jianda, 1998) So that means those cities try to make use of the same culture meanings derived from the same project or building. However, the tourism supported by the project or building's culture would not has the ideal effect. When the tourists find the same project or building that exist in the different cities, they would lose their interest. Zhuhai has New Yuanming Palace that is similar with the Yuanming Palace relics in Beijing, or in other words, Zhuhai's New Yuanming Palace imitates Beijing's New Palace, so the tourism result would not be satisfactory.

As for Zhuhai, the fault of New Yuanming Palace is that the tourism park is cut from the cultural background of Zhuhai. In Zhuhai of South China, such park can not easily display the cultural meanings, because the stories and historical meanings of Yuanming Palace is derived from Beijing, and the old building can display its full cultural meanings only in Beijing, where the relevant stories happened. New Yuanming Palace is typical in the cultural isolation, which means the project or building's culture has no connection with the cultural background of the local. What we should do is to connect the cultural different meanings. The abandoned factories are also cut off from the circumstance and the non-pollution industry development purpose.

It is apparent that the cultural meanings has intimate relationship with the stories or the poems, in other words, the cultural meanings are one kind of social meanings added in the physical existence. To connect the culturally isolated building or project with the existing cultural meanings in the local background is one way to derive the new cultural meanings. The other way to connect with the past history of the local is the reformation of the old building.

All those connections are necessary in the development of culture industry in Zhuhai. On the one hand, Zhuhai has short history, so the historical meanings in Zhuhai is scarce compared with other cities. On the other hand, Zhuhai has very few renowned stories that can make cultural sense. Besides, theoretically the using of the local existing resource to develop culture industry can save the much part of the budget. On the other hand, the existing resource has the unique indigenous cultural features, so the effect would be better than the brand-new building with the equal budget.

\section{Connection, Culture and Narrative}

Having illuminated the necessity to connect the buildings and projects of Zhuhai for cultural meanings, I will now move on to discuss the main buildings and projects that would be the subjects of such connection.

According to Kevin Lynch, path, edge, district, node and landmark is the key factors for appreciation of urban image. (Kevin Lynch, 1960). He also believed that most of the observers would appreciate the factors as a whole in different levels, such as community, city or metropolis. If we want to define Zhuhai's city image, we should not only analyze the five factors mentioned above, but also analyze the whole in different levels integrated by the five different factors.

In the whole, Zhuhai city is a new city without the long history, so the observers would only notice the fresh air and beautiful scenery, some parks and universities. Compared to the factors mentioned above, the folk culture and custom is not obvious. The cultural meanings derived from the parks and universities is obvious, especially in the east part of Zhuhai, where the citizen population concentrate. So in the sense, universities and parks would impress the tourists. However, the tourists still can not form the clear image of Zhuhai cultural image, because the universities and parks in Zhuhai city are not different from those of other cities.

In order to form the impressing image of Zhuhai city, Zhuhai city should form the cultural block by integrated the parks or universities. It is apparent that Jinan University and New Yuanming Palace 
have the advantage to be combined together. When New Yuanming Palace is integrated into Jinan University, the new cultural block is formed.

The abandoned plants are also the isolated ones results in the negative effect on the tourists. So combining the abandoned plants with the surrounding circumstance is necessary to develop cultural meanings. The main industry of Zhuhai is tourism, so the polluting factories were moved out in recent years. When the plants are abandoned, the isolation is obvious and forms the ugly scenery.

Most studies in culture industry of Zhuhai city have only focused on enlarging the investment for Zhuhai culture industry and developing the historical cultural meanings. A major problem with those researches is that the larger investment would not create cultural meanings well, because lots of the projects would result in the isolated meanings, which would exert weak effect on tourists. ${ }^{4}$ The culture is a kind of social messages of symbol, so if the buildings and projects have connections and the narrative effects, the cultural meanings would be more. It is apparent that Zhuhai's cultural existences are the isolated ones, so the stories or more meaningful implication would not be associated. There are many buildings and projects related with culture industry, however, their cultural meanings can not easily exert because there is no narrative about them.

\section{CONCLUSION}

This article set out to examine the condition of Zhuhai culture industry and find the way to improve its developing speed. This study has shown that the defects of Zhuhai culture industry and previous research about that and argued that the single investment in the culture industry with money or human resources would cause waste and inefficiency. The results of this research support the idea that using the existing projects and buildings will promote Zhuhai culture industry efficiently. The key point of such using is to connect the isolated objects to generate the new cultural meanings or narrative because the inefficiency of the cultural objects is caused by their isolated condition. There are two kinds of isolated cultural objects: the universities and the abandoned factories. Through integrating the park beside the universities, the park and the universities can all achieve their cultural efficiency. When the isolated factories is combined with their circumstance, they will exert the cultural function more. From the perspective of the cultural meaning generation, the defects of Zhuhai existing cultural buildings or projects are mainly about isolated condition. So the connection is one critical way to overcome the difficulty. The findings of this study suggest that connection can generate the new culture meanings, because the narrative and other cultural implication can be generated from the result of that process. The present study enhanced our understanding of the generation of urban culture. The scope of this study was limited in terms of area of Zhuhai. A further study could investigate the relationship between cultural meaning generation and connection of the existing urban objects more theoretically.

\section{REFERENCES}

Chen Changgui, From Zhuhai University to Zhuhai of University: Observing the Development of Zhuhai Higher Education from the Research Perspective. Journal of Higher Education. 2007(6), 38-43. (in Chinese)

Chen Huixian. The Four Hindrances for Zhuhai Culture Industry. Zhuhai Daily. August 1, 2007. 3

Cheng Ying. A Study on Design External Activity Space in the Creative Park Reformed from the Abandoned Factory. Master Thesis. Beijing University of Civil Engineering and Architecture. June 2014. 19. (in Chinese)

Fu Chonglan. Studies on New Urban. Xinhua Publishing house. 2005. 85. (in Chinese)

Guangdong Association of Higher Education Research, Innovation and Integration to Strengthen Zhuhai University Park Status Quo, Problems and Advices. Chinese Higher Education. 2012(11), 17-20.(in Chinese)

He Xin. Study on Current Situation and Development Approach of Culture Industry in Zhuhai. Master Thesis. Jilin University. May 2011

Huang Pangong. Studies on the Loft Culture in Reconstruction and Recycle of Old Industry Building. Master Thesis. Xi'an University of Architecture and Technology. June 2007.

\footnotetext{
${ }^{4}$ In recent years, some of culture industries are in deficit, which means those industries are not popular in Zhuhai city.
} 
Jinan University Zhuhai Campus. China University Teaching. 2010(12), .c1-c3.

Kevin Lynch, The Image of the City. MIT press. 1960

Xie Shisheng, Zhang Kaicheng. The Status Quo, Problems and Policy Response. Journal of Zhuhai Public Administration College. 2008(5), 51-64. (in Chinese)

Zhao Hong. Researching about the Urban Culture Construction in the Process of Urbanization. Master Thesis. Xi' an University of Construction and Technology. December, 2007. 1. (in Chinese)

Zhu Jianda. The Thinking about the Artificial Sensory Development. Urban Development. 1998(5), 46-47. (in Chinese) 